\title{
CARACTERIZAÇÃO FÍSICO-QUÍMICA E DESEMPENHO ELETROQUÍMICO DAS MEMBRANAS DE POLIBENCIMIDAZOL IMPREGNADAS COM KOH COMO ELETRÓLITO PARA CÉLULAS A COMBUSTÍVEL DE ÁLCOOL DIRETO ALCALINAS
}

\author{
RAFAELA NUNES COUTO ${ }^{1}$, JOSÉ J. LINARES ${ }^{1}$ \\ ${ }^{1}$ Universidade de Brasília, Instituto de Química, Divisão de Química Tecnológica \\ E-mail para contato: joselinares@unb.br
}

\begin{abstract}
RESUMO - O presente trabalho apresenta os resultados mais importantes obtidos na caracterização físico-química das membranas de polibencimidazol (PBI) impregnadas com $\mathrm{KOH}$ para seu uso em uma célula a combustível alcalina de membrana polimérica. $\mathrm{O}$ PBI, pelo caráter anfotérico, possui uma elevada capacidade de impregnação com $\mathrm{KOH}$, chegando a absorver até 5 moléculas por unidade de repetição do polímero quando submerso em uma solução $6 \mathrm{~mol} \mathrm{~L}^{-1} \mathrm{KOH}$. A cristalinidade da membrana resultante mostra a presença do $\mathrm{KOH}$ na estrutura, o que também é confirmado pelos espectros de FTIR. A estabilidade térmica em ar se encontra garantida até $300^{\circ} \mathrm{C}$. Finalmente, a permeabilidade ao etanol e glicerol se incrementa com a temperatura, com valores em sintonia com outros apresentados na literatura, junto com uma condutividade iônica satisfatória acima de $0,01 \mathrm{~S} \mathrm{~cm}^{-1}$. Os resultados na célula unitária confirmam o bom desempenho deste material como eletrólito polimérico para meio alcalino.
\end{abstract}

\section{INTRODUÇÃO}

A operação das células a combustível em meio alcalino apresenta algumas vantagens importantes com relação às homólogas em meio ácido (Antolini e Gonzalez, 2010). A vantagem mais relevante vem da melhora da cinética das reações eletroquímicas, tanto na redução de oxigênio, quanto na oxidação do combustível. Especialmente relevante é esta melhora no caso da operação com álcoois, tal como mostrado na literatura (Merle et al., 2011). Aliás, a operação neste meio permite substituir à platina, cujo uso constitui um dos empecilhos mais importantes para a comercialização das células a combustível de baixa temperatura. Materiais alternativos tais como Ag (Wang et al., 2014) ou óxidos de manganês (Garcia et al., 2014) têm mostrado um ótimo desempenho no cátodo. Da mesma forma, catalisadores anódicos baseados em Au e Pd também têm se postulado como alternativas à platina, além de óxidos de Ni (Oliveira et al., 2014).

No entanto, o grande problema para o desenvolvimento deste tipo de sistema é a membrana polimérica de troca aniônica. Existem diferentes tipos de materiais, tal como recolhido por Merle et al. (2011). Porém, a grande maioria desses materiais apresentam problemas de estabilidade a longos tempos operativos devido a uma significativa degradação em meio alcalino (An et al., 2012). Uma 
alternativa interessante é o uso do polibencimidazol impregnado com $\mathrm{KOH}$. Este material por se mesmo apresenta uma ótima resistência mecânica, química e térmica (Lobato et al., 2006). Em meio alcalino, este material já tem apresentado bons resultados na operação com metanol (Hou et al., 2008a) e etanol (Hou et al., 2008b). Para poder conseguir estes resultados, o PBI impregnado com $\mathrm{KOH}$ deve apresentar umas propriedades físico-químicas adequadas ao meio de trabalho. Desta forma, o intuito deste trabalho é caracterizar físico-quimicamente as membranas de PBI impregnadas com KOH. Para isso, foi avaliada a capacidade de impregnação do PBI com o álcali, a cristalinidade da membrana resultante, a estrutura através de espectros de FTIR, a estabilidade térmica, e, do ponto de vista da célula, a permeabilidade aos álcoois candidatos (etanol e glicerol) e a condutividade, juntos com resultados na célula unitária que complementaram a caracterização.

\section{MATERIAL E MÉTODOS}

As membranas de polibencimidazol utilizadas neste estudo foram fornecidas pela empresa Danish Power System (Daposy). Estas membranas possuem uma espessura aproximada de 60 microns. Os estudos de capacidade de absorção de $\mathrm{KOH}$ foram realizados mediante imersão das membranas de PBI em banhos do álcali de diferente concentração por uma semana. Transcorrida este tempo as membranas foram secadas superficialmente com ajuda de papel de filtro e pesadas. Para as medidas de difração de raios $\mathrm{X}$ das membranas foi utilizado um equipamento D8 Focus da Rigaku Corp. (Japão) entre ângulos $2 \theta 10-75^{\circ}$ operando com radiação $\mathrm{K}_{\alpha}$ do $\mathrm{Cu}(\lambda=0.15406 \mathrm{~nm})$. Para os espectros de FTIR foi usado um equipamento 640-IR FT-IR Espectrômetro da Agilent Technologies, varrendo entre 4000 e $600 \mathrm{~cm}^{-1}$. As análises termogravimétricas foram realizadas em um equipamento Shimadzu DTG-60, aquecendo as amostras entre 25 e $300^{\circ} \mathrm{C}$ com uma razão de aquecimento de $10^{\circ} \mathrm{C}$ $\min ^{-1}$. Para as medidas de permeabilidade foi utilizada uma célula cujo esquema se mostra na Figura 1, medindo-se a concentração de álcool com ajuda de um espectrofotômetro UV-Vis.

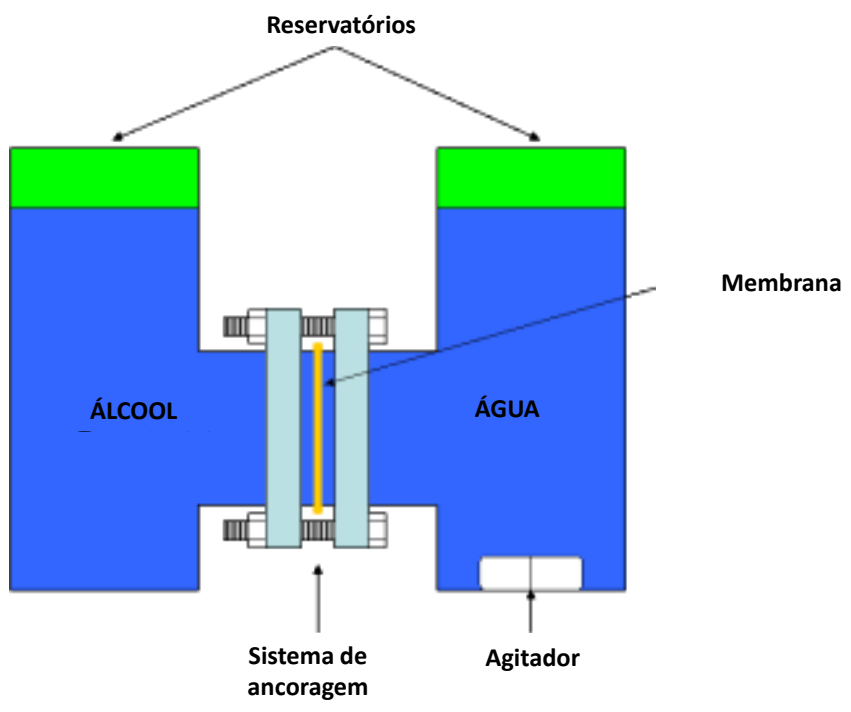

Figura 1. Esquema básico do sistema para avaliação da permeabilidade da membrana 


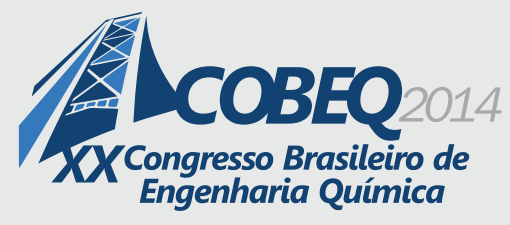

19 a 22 de outubro de 2014
Florianópolis/SC

As medidas de condutividade foram realizadas com ajuda de um potenciostato/galvanostato PGSTAT 302 com módulo de impedância da Metrohm Autolab. As medidas foram feitas a uma diferença de potencial de $0 \mathrm{~V}$, aplicando uma onda sinusoidal de voltagem de $5 \mathrm{mV}$ rms em uma faixa de frequências de $10 \mathrm{KHz}$ a $1 \mathrm{KHz}$. As medidas foram feitas no sistema de célula a combustível com eletrodos previamente preparados com Pt/C (20\% de metal, BASF Fuel Cells), contendo um 10\% de Nafion $^{\circledR}$. A carga de metal no ânodo foi de $2 \mathrm{mg} \mathrm{cm}^{-2}$ para o ânodo e $1 \mathrm{mg} \mathrm{cm}^{-2}$ para o cátodo. A membrana foi colocada no meio reativo da célula, sendo usado uma solução de $1 \mathrm{~mol} \mathrm{~L}^{-1}$ de glicerol e $4 \mathrm{~mol} \mathrm{~L}^{-1} \mathrm{KOH}$ no ânodo e oxigênio no cátodo. As vazões respectivas foram de $1 \mathrm{~mL} \mathrm{~min}^{-1}$ para o

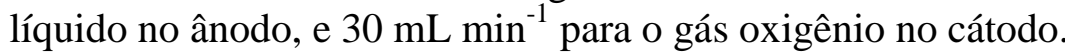

$\mathrm{Na}$ célula a combustível foram utilizados eletrodos preparados a partir da deposição da tinta mencionada anteriormente sobre uma camada difusora de tecido de carbono com camada microporosa. A carga total de metal foi a mesma que no caso das medidas de condutividade. Uma vez preparados os eletrodos, e após o processo de secagem, estes foram colocados entre uma membrana de PBI previamente impregnada com $4 \mathrm{~mol} \mathrm{~L}{ }^{-1} \mathrm{KOH}$. A união entre os eletrodos e a membrana foi realizada mediante com ajuda da própria pressão de fechamento da célula unitária. A estrutura desta está formada por duas placas de grafite onde se usinaram canais com geometria paralela, suportadas sobre placas de alumínio. A impulsão da solução anódica foi realizada com ajuda de uma bomba de diafragma. A regulação da vazão do cátodo foi realizada com ajuda de um rotâmetro. As curvas de polarização foram realizadas em modo galvanostático, sendo usado o potenciostato/galvanostato PGSTAT 302, deixando um tempo de 5 minutos por cada valor de corrente.

\section{RESULTADOS E DICUSSÃO}

A Figura 2 mostra o nível de impregnação da membrana de PBI para as diferentes concentrações do banho de $\mathrm{KOH}$. Como pode ser observado, conforme aumenta a concentração de $\mathrm{KOH}$, incrementa-se da mesma forma a quantidade de $\mathrm{KOH}$ dentro da membrana. Atendendo à estrutura do polímero (ver inserção em Fig. 2), além da substituição do H do anel imidazólico pelo cátion do álcali, duas moléculas de $\mathrm{KOH}$ poderiam interagir diretamente com os dois átomos de nitrogênio do anel imidazólico da unidade de repetição do PBI mediante ponte de hidrogênio. Isto demonstra a existência de uma certa quantidade $\mathrm{KOH}$ ligada quimicamente à estrutura do PBI. O elevado número de moléculas de $\mathrm{KOH}$ por unidade de repetição é responsável pelo adequado comportamento deste material como membrana eletrolítica para meio alcalino, como será descrito mais tarde.

Na Figura 3 são apresentados os difratogramas das membranas de PBI. O material sem impregnar com $\mathrm{KOH}$ apresenta a forma típica correspondente ao sinal de um material amorfo, com um pico largo centrado entorno do ângulo $2 \theta$ de $24^{\circ}$ correspondente ao halo do amorfo. No caso do material impregnado com $\mathrm{KOH}$, pode ser observada a aparição de vários picos associados ao $\mathrm{KOH}$ a ângulos de 11,9, 14,2, 17,4, 31,4 e menos intenso de $66^{\circ}$. Estes picos são devidos à formação de cristais de $\mathrm{KOH}$ (Hou et al., 2008a) dentro da estrutura da membrana, conferindo a capacidade do polímero para alojá-lo. Isto será de vital importância para fornecer ao material a condutividade iônica necessária para posterior uso na célula a combustível. 


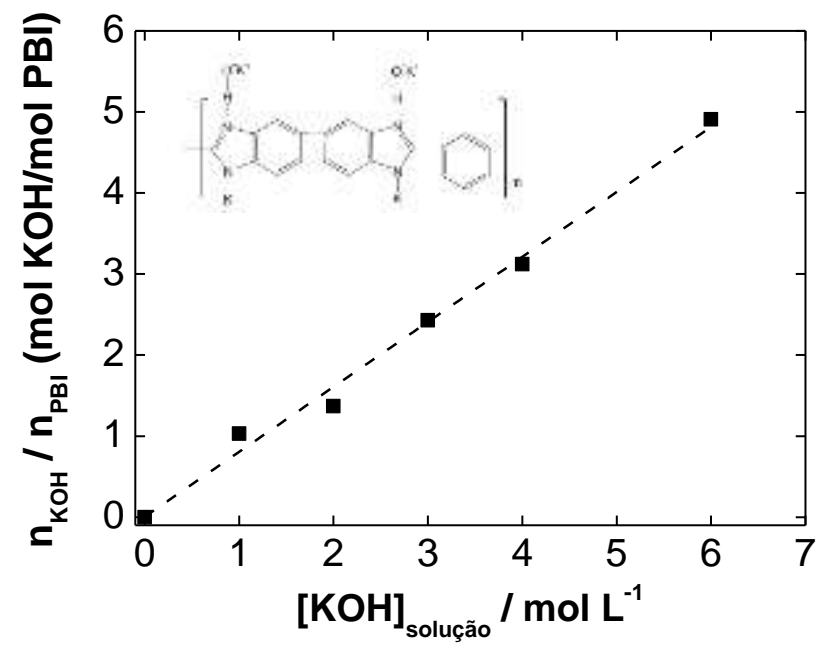

Figura 2. Nível de impregnação de KOH das membranas de PBI para diferentes concentrações daquele no banho de impregnação

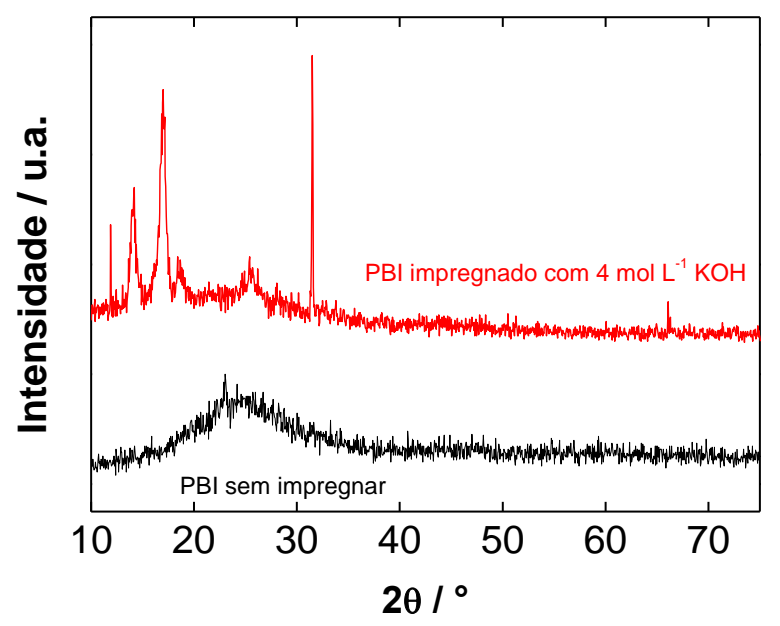

Figura 3. Difratogramas das membranas de PBI

Os espectros de infravermelho das membranas de PBI são apresentados na Figura 4. Como pode ser observado, a impregnação do PBI com $\mathrm{KOH}$ provoca mudanças nos espectros e, portanto, na estrutura do polímero. De especial significância são o pico aparecido a $1410 \mathrm{~cm}^{-1}$, associada ao modo de flexão da ligação O-H, resultante da interação do polímero com o álcali. Aliás, a presença do $\mathrm{KOH}$ na estrutura da membrana também intensifica os sinais a 1625, 1560 e $1430 \mathrm{~cm}^{-1}$ associado aos modos de esticamento das ligações $\mathrm{C}=\mathrm{C}$ e $\mathrm{C}=\mathrm{N}$, e particularmente à interação por pontes de hidrogênio entre o grupo -OH do álcali e o nitrogênio do anel imidazólico com dois elétrons livres (Luo et al., 2012). 


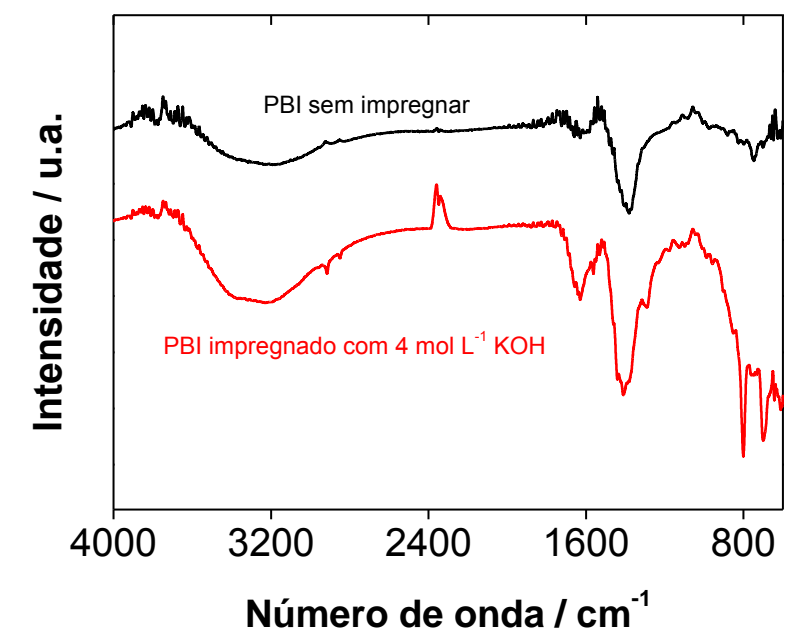

Figura 4. Espectros de infravermelho das membranas de PBI

A estabilidade térmica do polímero foi avaliada por meio de análises termogravimétricas (Figura 5). Como pode ser observado, em ambos os casos, até $300^{\circ} \mathrm{C}$, apenas existe uma queda associada à perda associada à agua de hidratação do $\mathrm{PBI}$, com um valor aproximado do $12 \%$ de peso até $150^{\circ} \mathrm{C}$. No caso da membrana impregnada com $\mathrm{KOH}$, existe também uma única perda até $200^{\circ} \mathrm{C}$, neste caso do $17 \%$. Este valor levemente superior se deve à agua retida pelo $\mathrm{KOH}$ devido à natureza higroscópica deste (Hou et al., 2008a). A Fig. 5 confirma a estabilidade térmica das membranas de PBI impregnadas com $\mathrm{KOH}$ até temperaturas intermediárias de $150-200^{\circ} \mathrm{C}$ sem degradação do material, mostrando que, em termos de estabilidade térmica, o PBI impregnado com $\mathrm{KOH}$ é um material adequado para o uso na célula unitária.

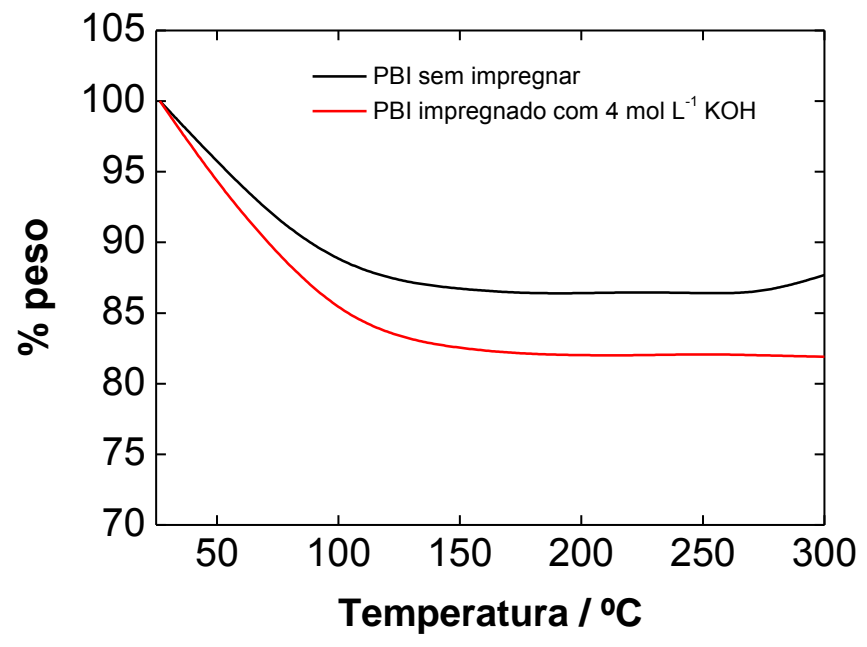

Figura 5. Termogramas das membranas de PBI 
A permeabilidade ao glicerol e ao etanol das membranas de PBI se mostra na Figura 6. Como pode ser observado, existe um incremento na permeabilidade dos dois álcoois com a temperatura, devido ao aumento do coeficiente de difusão do soluto através da membrana com a temperatura para os dois álcoois. Os valores do glicerol são inferiores aos correspondentes do etanol, provavelmente devido ao maior tamanho desta molécula comparado com o etanol, porém se encontram na linha de outros materiais usados como filmes poliméricos (An et al., 2012).
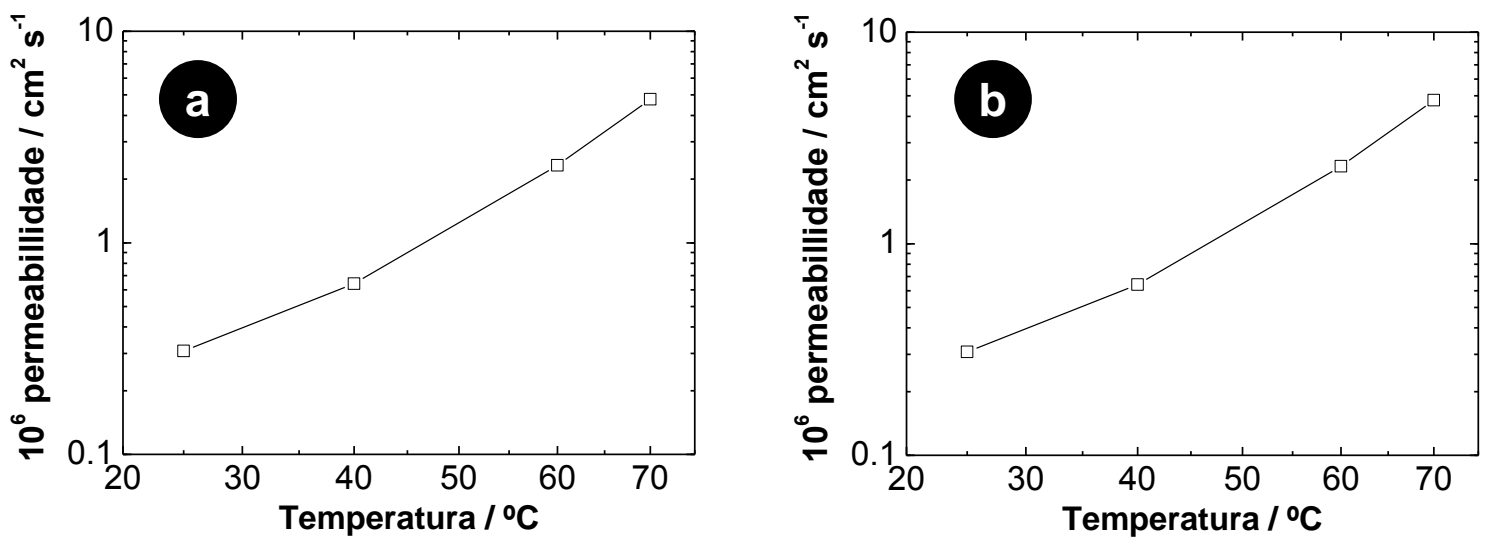

Figura 6. Permeabilidade ao: a) glicerol $\left(1 \mathrm{~mol} \mathrm{~L}^{-1}\right)$, e b) etanol $\left(2 \mathrm{~mol} \mathrm{~L}^{-1}\right)$ das membranas de PBI em meio $4 \mathrm{~mol} \mathrm{~L}^{-1}$ de $\mathrm{KOH}$

O teste final para comprovar a validez de um determinado material como eletrólito polimérico em célula a combustível são as medidas de condutividade iônica e os resultados na célula unitária. $\mathrm{Na}$ Figura 7 se mostram os resultados correspondentes a estas medidas. No caso da condutividade, foram realizadas medidas a diferentes temperaturas para o nível de impregnação $4 \mathrm{~mol} \mathrm{~L}^{-1}$. Nas curvas de polarização se trabalhou com etanol e glicerol a $60^{\circ} \mathrm{C}$, sendo usado oxigênio industrial no cátodo.
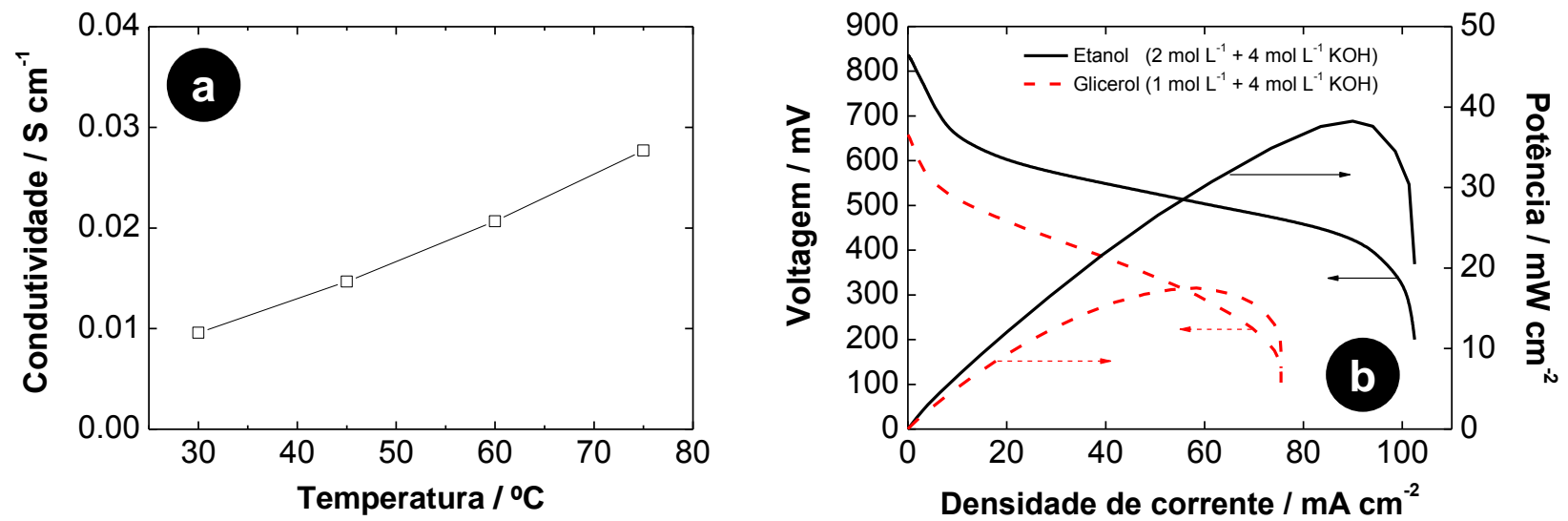

Figura 7. a) Medida da condutividade para diferentes temperatura após impregnar a membrana em banho de $\mathrm{KOH} 4 \mathrm{~mol} \mathrm{~L}^{-1}$, b) Curvas de polarização $60^{\circ} \mathrm{C}$ para os diferentes combustíveis. 


\section{9 a 22 de outubro de 2014 \\ Florianópolis/SC}

Como pode ser observados, os valores da condutividade se encontram acima do valor limite de

$0,01 \mathrm{~S} \mathrm{~cm}^{-1}$, suficientemente elevado para garantir um adequado funcionamento da célula a combustível sem perdas ôhmicas excessivas, mostrando a boa predisposição do PBI impregnado com $\mathrm{KOH}$ como eletrólito polimérico. Isto é plenamente confirmado por meio dos resultados do desempenho na célula a combustível operando com o glicerol e o etanol como combustível. Resultados preliminares mostram máximos de potência no caso do primeiro de $17,5 \mathrm{~mW} \mathrm{~cm} \mathrm{~cm}^{-2}$ e de $38,2 \mathrm{~mW} \mathrm{~cm}$ no segundo, corroborando o bom posicionamento deste material para ser utilizado como membrana polimérica para sistemas baseados em álcoois em meio alcalino.

\section{CONCLUSÕES}

O presente trabalho mostra os resultados da caracterização físico-químicas das membranas de PBI impregnado com $\mathrm{KOH}$, candidatas atrativas para células de filme polimérico alcalinas utilizando álcoois como combustível. O PBI apresenta uma elevada capacidade de absorção de $\mathrm{KOH}$, até 5 moléculas por unidade de repetição quando é impregnado em um banho com uma concentração 6 mol $\mathrm{L}^{-1}$ do álcali. Este se integra dentro da estrutura da membrana, tal como refletido pelos difratogramas e espectros de infravermelho, não influenciando negativamente na estabilidade térmica da membrana na faixa de até $300^{\circ} \mathrm{C}$. Os coeficientes de permeabilidade mostrados estão na linha de outras membranas de troca aniônica, com o aumento esperado com a temperatura. Finalmente, a membrana apresenta valores de condutividade iônica suficientemente altos para sua implementação na célula a combustível, cujo desempenho preliminar tem sido evidenciado, mostrando máximos de potência de $17,5 \mathrm{~mW} \mathrm{~cm}^{-2}$ para o glicerol e de $38,2 \mathrm{~mW} \mathrm{~cm}^{-2}$ para o etanol.

\section{AGRADECIMENTOS}

Os autores agradecem ao Instituto de Química de São Carlos (Universidade de São Paulo) pela gentil doação das membranas de PBI e os catalisadores utilizados neste estudo.

\section{REFERÊNCIAS}

AN, L.; ZHAO, T.S.; WU, Q.X.; ZENG, L. Comparison of different types of membrane in alkaline direct ethanol fuel cells. Int. J. Hydrogen Energ., v. 37, p. 14536-14542, 2012.

ANTOLINI, E.; GONZALEZ, E.R. Alkaline direct alcohol fuel cells. J. Power Sources, v. 195, p. 3431-3450, 2010.

GARCIA, A.; LINARES, J.J.; CHATENET, M.; TICIANELLI, E.A. NiMnOx/C: A Non-noble Ethanol-Tolerant Catalyst for Oxygen Reduction in Alkaline Exchange Membrane DEFC. Electrocatal., v. 5, p. 41-49, 2014.

HOU, H.; SUN, G.; HE, R.; SUN, B.; JIN, W.; LIU, H.; XIN Q. Alkali doped polybenzimidazole membrane for alkaline direct methanol fuel cell. Int. J. Hydrogen Energ., v. 33, p. 7172-7176, 2008 a.

HOU, H.; SUN, G.; HE, R.; WU, Z.; SUN, B. Alkali doped polybenzimidazole membrane for high performance alkaline direct ethanol fuel cell. J. Power Sources, v. 182, p. 95-99, 2008 b.

LOBATO, J.; CAÑIZARES, P.; RODRIGO, M.A.; LINARES J.J.; MANJAVACAS, G. Synthesis 
and characterisation of poly[2,2-(m-phenylene)-5,5-bibenzimidazole] as polymer electrolyte membrane for high temperature PEMFCs. J. Membr. Sci., v. 280, p. 351-362, 2006.

LUO, H.; VAIVARS, G.; AGBOOLA, B.; MU, S., MATHE, M. Anion exchange membrane based on alkali doped poly(2,5-benzimidazole) for fuel cell. Solid State Ionics, v. 208, p. 52-55, 2012.

MERLE, G.; WESSLING, M.; NIJMEIJER, K. Anion exchange membranes for alkaline fuel cells: A review. J. Membr. Sci., v. 377, p. 1-35, 2011.

OLIVEIRA, V.L.; MORAIS, C.; SERVAT, K.; NAPPORN, T.W.; TREMILIOSI-FILHO; G.; $\mathrm{KOKOH}, \mathrm{K} . \mathrm{B}$. Studies of the reaction products resulted from glycerol electrooxidation on Ni-based materials in alkaline medium. Eletrochim. Acta, v. 117, p. 255-262, 2014.

WANG, W.; XIN, L.; ZHAO, X.; QIU, Y.; ZHANG, Z.; BATURINA, O.A.; LI, W. Carbon supported Ag nanoparticles with different particle size as cathode catalysts for anion exchange membrane direct glycerol fuel cells. Renew. Energ., v. 62, p. 556-562, 2014. 